\title{
O partidarismo no Brasil (2002/2010)
}

\section{Luciana Fernandes Veiga}

Universidade Federal do Paraná

Resumo: Este trabalho tem como objetivos monitorar o tamanho da onda decrescente da identidade partidária e de sua onda reversa; acompanhar as mudanças nos perfis dos eleitores no que se refere à escolaridade, região e ideologia; contribuir para o debate sobre a composição da mudança com análise da taxa de identidade partidária em meio a diferentes segmentos sociais. Constata-se que o perfil dos eleitores partidários no Brasil, após sofrer não desprezíveis mudanças em um período curto, encontra-se em 2010 com mais escolaridade do que em 2006; mais voltado para o Norte/Centro Oeste e o Nordeste e mais conservador do que nos dois outros momentos.

Palavras chaves: Identidade partidária, partidos políticos, PT, CSES-ESEB 2010.

Abstract: The aim of this article is to evaluate the oscilating wave of party identity, to explain the changes of the characteristics of the electorate, in what relates to the level of education, ideology and region, and to contribute to the debate about party identity chagings among different social groups. The profile of voters with party identity Brazil in 2010 shows higher levels of education than in 2006, is more located in the Northeast and North/Centerwest regions and is more conservative than in other periods.

Keywords: party identity, political parties, Worker's Party, CSES-ESEB 2010 


\section{Introdução}

Em 2002, a primeira rodada do Estudo Eleitoral Brasileiro - ESEB apontou que $39 \%$ dos eleitores em nosso país tinham identidade partidária. Em 2006, a segunda rodada da pesquisa indicou uma queda de 11 pontos percentuais em tal taxa, a identidade partidária se restringia então a $28 \%$ do eleitorado. Nos quatro anos seguintes, verifica-se a onda reversa, a identidade partidária cresce entre os brasileiros em 11,2 pontos percentuais, de acordo com o ESEB 2010.

Neste movimento de descida e subida do percentual da identidade partidária, destaca-se o vínculo do eleitorado com o Partido dos Trabalhadores (PT). Os números das duas primeiras rodadas do ESEB assinalam que, de 2002 a 2006, o partido perdeu 5 pontos percentuais de eleitores identificados com a legenda, da taxa de $23 \%$ passou a $18 \%$. Naquele momento, nenhuma das grandes legendas nacionais foi capaz de angariar partidários, tendo aumentado o número de brasileiros sem identidade partidária a patamares próximos daqueles verificados na década de 1980, quando o nosso sistema de partidos estava no início de sua institucionalização com a volta do multipartidarismo pós-ditadura. Não obstante, é o próprio PT que protagoniza a retomada da identidade partidária no período de 2006 a 2010, quando vê crescer o vínculo com a legenda em 6,5 pontos percentuais.

A volatilidade de tais números em um curto período de tempo chama ainda mais a atenção se pensarmos no fundamento da identidade partidária. O conceito de identidade partidária está associado a uma relativa estabilidade entre os pleitos. Para Dalton e Wattenberg (2002), o vínculo partidário seria como uma âncora política, impedindo que os eleitores fossem levados por ondas momentâneas, proporcionando um comportamento mais estável no sistema democrático. Logo mencionaremos como acontecimentos que marcaram os mandatos de Luiz Inácio Lula da Silva (PT) foram capazes de desalinhar e realinhar em boa parte o vínculo entre partidos e eleitores no país.

Este artigo tem três objetivos, todos de caráter descritivo. Interessa-nos mensurar a variação da taxa de identidade partidária no período de 2002 a 2010 com foco nos quatro maiores partidos brasileiros: o Partido dos Trabalhadores (PT), - Partido do Movimento Democrático Brasileiro (PMDB), o Partido da Social Democracia Brasileira (PSDB) e o Democratas (DEM). Buscaremos identificar as mudanças e continuidades no perfil dos eleitores partidários brasileiros no que tange à escolaridade, região e ideologia. Por fim, identificaremos em que estratos do eleitorado ocorreram as perdas e os ganhos de identidade partidária, tendo o controle das variáveis acima citadas. A decisão de abordar tais variáveis está baseada em estudos anteriores (VEIGA, 2007; SAMUELS, 2008, VENTURI, 2010, 
SINGER, 2010) que apontaram alterações nos perfis dos eleitores partidários e petistas nestes aspectos no decorrer dos últimos anos. Assim, buscaremos monitorar tais variações. Para este estudo, serão utilizados os dados das três rodadas do ESEB realizadas em 2002, 2006 e 2010.

\section{A variação da taxa de identidade partidária (2002/2010)}

Não são poucos os estudos que destacam a propensão de queda da identidade partidária entre os eleitores nas democracias contemporâneas (DALTON E WATTENBERG, 2002). Para além da redução da taxa, verifica-se uma tendência de mudança quanto àqueles perfis tradicionais descritos por Campbell et all.(1960) de acordo com o qual o eleitor partidário seria detentor de mais conhecimento sobre a política e mais mobilizado e, por sua vez, o eleitor não partidário seria menos educado, detentor de pouca informação e não envolvido em eleições. Dalton (2008) sugere a existência de dois outros tipos de eleitores, os partidários rituais e os apartidários. O primeiro grupo seria composto por eleitores com baixo discernimento sobre os temas da política, mas mobilizados, sendo bastante sensíveis aos resultados das políticas públicas. Já o segundo grupo seria composto por votantes esclarecidos, mas que buscam outros canais para sua participação política, diferente do canal partidário. Ou seja, a depender do que tem sido detectado nas democracias contemporâneas, haveríamos de esperar encontrar aqui no Brasil queda na identidade e mudança do perfil do eleitor partidário, agora podendo ser ele menos estudado.

Mesmo diante de tais achados no âmbito internacional, Kinzo (2007) chegou a esperar que no Brasil, dado o contexto particular de retomada de eleições diretas para os cargos majoritários no decorrer dos anos 80, a experiência contínua de pleitos com os mesmos partidos protagonizando as disputas faria crescer a lealdade partidária. No entanto, ao se debruçar sobre os dados do Instituto Datafolha, verificou que, ao contrário do que esperava, a preferência partidária no período de 1989 a 2002 foi reduzida, a despeito inclusive da realização de três disputas presidenciais, quando supostamente os partidos seriam referências importantes. Kinzo, então, propõe que os partidos estariam priorizando candidaturas pessoais, em detrimento do desenvolvimento de laços entre partidos e eleitores.

De acordo com o histórico de pesquisas Ibope, Perseu Abramo, Datafolha e Criterium elaborado por Venturi (2010), no período de 1987 a 2010, constata-se que os números de eleitores sem preferência partidária podem variar entre $64 \%$ a $38 \%$ do eleitorado. O estágio de maior fragilidade da identidade partidária foi detectado em julho 1987, no momento inicial da mensuração pelos institutos e 
quando o sistema multipartidário brasileiro estava se restabelecendo. E a única vez que se verifica novamente tal desvinculação entre eleitores e partidos é em dezembro de 2005, sob o efeito da série de denúncias de corrupção envolvendo, sobretudo o PT e o Governo Lula, quando o número de eleitores sem preferência partidária alcançou o patamar de $62 \%$. Na maior parte do tempo, tal percentual varia de 52 a 59 pontos.

A respeito da distribuição da preferência entre os partidos, tem-se que até 1994 o partido que mais despertava a preferência partidária era o PMDB. No entanto, desde a sua criação, a preferência partidária pelo PT veio paulatinamente aumentando. Especificamente de 1989 a 1994, o partido passou de uma adesão de $8 \%$ do eleitorado para alcançar 21\%. No decorrer dos anos 90, PT e PMDB disputaram a preferência do eleitorado brasileiro, cada um atingindo aproximadamente $20 \%$ de vínculos partidários. A partir de então, o PMDB viu o seu elo com os eleitores se atenuar, e o PT, no decorrer 1997 a 2005, viu a sua taxa de preferência partidária crescer, alcançando $27 \%$ do total do eleitorado (VENTURI, 2010).

Sobre o PFL - o Partido da Frente Liberal, agora DEM - verifica-se que ele obteve o seu ápice em 1997, quando atingiu 7\% de identidade partidária. O PSDB, a despeito de ocupar o Governo Federal com Fernando Henrique Cardoso de 1994 a 2002 e de ter candidatos com potencial nas disputas presidenciais (José Serra em 2002 e 2010 e Geraldo Alckmin em 2006), não conseguiu expandir a sua taxa de identidade partidária (KINZO, 2007).

Kinzo (2007) destaca que fatores organizacionais ajudam a explicar o desempenho diferenciado do PT. A começar pela sua origem, um partido de massa advindo dos movimentos sociais do início da década de 1980, demarcando desde o começo uma imagem nítida de esquerda, mantendo-se sempre na oposição dos governos que se aproximavam da tendência mais neo-liberal, que marcou as duas últimas décadas do século XX. Ademais, a autora justificava a presença de mais laço partidário do eleitorado com o PT pela estratégia da legenda de dar mais ênfase ao partido enquanto uma organização política.

De posse deste resgate, agora com o olhar para os dados do ESEB, podemos verificar que em 2002 manteve-se a tendência que vinha sendo reforçada desde 1994 de ser o PT uma legenda forte e francamente favorita do eleitorado. Esta disposição é pela primeira vez colocada em xeque em 2005, e o resultado foi a perda de cinco pontos percentuais mensurados pelo ESEB em 2006. De 2006 a 2010, tem-se a retomada da identidade partidária em 6,5 pontos, com o PT resgatando o prestígio do momento anterior a 2005.

O marco de 2005 é a crise do Mensalão, com denúncias de corrupção envolvendo lideranças petistas. Venturi (2010) destaca três fatores que acredita 
convergir para o entendimento deste movimento de abrupta perda acompanhada de rápida retomada da identidade partidária: a) o desgaste das outras legendas perante a opinião pública, em contraposição ao enraizamento social do PT desde a sua origem e ao ganho gradual de legitimidade com a sua atuação nos governos municipais e estaduais; b) a percepção de que, se verdadeiro, o comportamento de petistas acusados de corrupção envolvendo financiamento paralelo de campanhas não se constituía uma novidade na política; e c) os resultados positivos do governo Lula na melhoria da qualidade de vida das pessoas.

Curiosa também é a situação do PMDB. Com a curva de identidade partidária acentuadamente decrescente nos últimos anos, ele obtém em 2010 apenas $2,5 \%$ de partidários a despeito de ter elegido a segunda maior bancada para a Câmara dos Deputados no mesmo ano com 79 parlamentares. Samuels (2004) já comentara que a distribuição do partidarismo tem um 'quê' de enviesamento, na medida em que partidos que conseguem atingir alto potencial de votos em eleições legislativas nacionais não aparecem na mesma proporção nas manifestações de preferências dos eleitores.

Em síntese, a despeito dos movimentos das taxas de identidade partidária em outras democracias contemporâneas, aqui no Brasil, no total do período em foco, não foi registrado o seu decréscimo.

Tabela 1

Partido com o qual tem identidade, para eleitores brasileiros, 2002/2006/2010 (\%)

\begin{tabular}{||c|c|c|c||}
\hline PARTIDOS & $\mathbf{2 0 0 2}$ & $\mathbf{2 0 0 6}$ & $\mathbf{2 0 1 0}$ \\
\hline Geral & 39 & 28 & 39,2 \\
\hline PT & 23 & 18 & 24,5 \\
\hline PMDB & 4 & 4 & 2,7 \\
\hline PFL & 2 & 1 & 0,5 \\
\hline PSDB & 4 & 4 & 5,7 \\
\hline Outros & 6 & 1 & 5.8 \\
\hline
\end{tabular}

Fonte: ESEB, 2002, 2006, 2010.

\section{Mudanças e continuidades no perfil dos eleitores partidários}

Uma vez constatado que houve uma onda de perda de identidade partidária de 2002 a 2006 e uma onda reversa de 2006 a 2010, uma dúvida se coloca: quais foram as mudanças e as continuidades no perfil dos eleitores partidários nestes três 
momentos? De posse de tal resposta, outro questionamento se apresenta: Como se constituiu tal mudança de perfil? Analisaremos os seguintes aspectos do eleitorado: a escolaridade, a região e a ideologia.

Uma vez verificada a perda da identidade partidária e o seu impacto dentro do PT no período de 2002 a 2006, alguns estudiosos voltaram o olhar para o fenômeno. Veiga (2007) constatou que os eleitores com vínculo com o PT apresentavam em 2006 um perfil menos escolarizado, com uma postura menos à esquerda e mais ao centro do espectro ideológico, e com menos presença no Sudeste e mais presença no Nordeste do que em 2002. Samuels (2008) buscou reduzir o impacto da mudança, afirmando ter verificado um baixo grau de alteração nas bases do petismo. Mas confirmou que o eleitorado com identidade partidária com o PT estava então menos escolarizado, com ideologia levemente mais moderada e menos concentrado na região Sudeste. Coloca em dúvida, no entanto, se tal mudança teria ocorrido apenas no período de 2002 a 2006 ou se já iniciara antes da chegada de Lula ao Governo Federal, ainda nos anos 90.

Os achados de Venturi (2010) corroboram o que foi encontrado por Veiga no sentido que houve uma popularização do partido. Ele ainda apresenta números que atenuam a dúvida apresentada por Samuels, ao afirmar que a mudança na composição social da preferência partidária pelo PT aconteceu de forma gradual e já era observável nas eleições de 2002, quando os eleitores com renda familiar até dois salários mínimos passaram a ser responsáveis por cerca de metade dos petistas - uma alteração que se acentua em 2006, reconhece, mas que já marcara forte presença, no entanto, quatro anos antes. O autor ainda aponta que no processo teria havido antes um crescimento da adesão popular ao PT do que uma troca de estratos sociais, com a entrada dos segmentos de mais baixa renda e com a saída das classes médias e alta.

Singer (2010) termina por agregar a sugestão de Veiga (2007) e os achados de Venturi (2010) com uma resposta dupla ao propor que o partido já havia se popularizado ao receber um apoio inédito de eleitores de menor renda em 2002 e sofreu uma nova onda de popularização, por subtração, ao perder a simpatia no eleitorado de classe média, estando o PT agora, em boa parte, sustentado pelo apoio conquistado em 2002.

Tal discussão motivou o segundo e o terceiro objetivos específicos deste trabalho, que seja monitorar as variações no perfil dos identificados, e ainda, identificar a composição da mudança. 


\section{Escolaridade. A evolução do perfil}

No eleitorado de 2002 a 2006, houve redução de escolaridade quando tomamos como medida a moda, entre os eleitores partidários e entre aqueles com vínculo com alguma das quatro legendas sob análise, exceção para o PMDB. A moda, neste caso, nos indica qual é o grau de escolaridade mais freqüente no grupo sob análise. No caso do PT, em 2002, os partidários com ensino médio eram os mais freqüentes, já em 2006, os mais comuns eram os eleitores analfabetos ou com até quatro anos de estudo. Neste caso, podemos verificar que a escolaridade, do eleitor partidário e do eleitorado em geral é maior do que aquela identificada entre os petistas em 2006. No eleitorado e entre os partidários, a instrução mais freqüente em 2006 foi aquela na faixa de quatro a oito anos de estudo.

Já de 2006 para 2010, ainda com olhar para a moda, nota-se o aumento do grau de instrução no eleitorado, nos partidários e naqueles que apresentam vínculo com o PT e o DEM, e nota-se a manutenção da escolaridade entre os vinculados ao PSDB, definindo como padrão do eleitor, aquele com ensino médio, independente de sua identidade partidária, exceção, novamente, apenas para o PMDB (Tabela 2). 
Tabela 2

Escolaridade do eleitorado, dos eleitores partidários e dos partidários identificados com PT, PMDB, DEM/PFL e PSDB (moda) - 2002, 2006 e 2010

\begin{tabular}{|c|c|c|c|c|c|c|c|c|c|c|c|c|c|c|c|c|c|}
\hline \multicolumn{3}{|c|}{ Eleitorado $^{1}$} & \multicolumn{3}{|c|}{ Partidários } & \multicolumn{3}{|c|}{ PT } & \multicolumn{3}{|c|}{ PMDB } & \multicolumn{3}{|c|}{ DEM/PFL } & \multicolumn{3}{|c|}{ PSDB } \\
\hline 2002 & 2006 & 2010 & 2002 & 2006 & 2010 & 2002 & 2006 & 2010 & 2002 & 2006 & 2010 & 2002 & 2006 & 2010 & 2002 & 2006 & 2010 \\
\hline 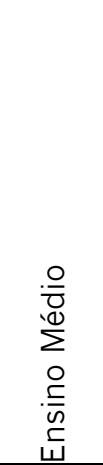 & 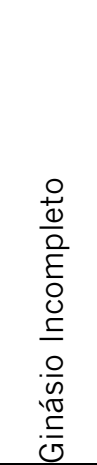 & 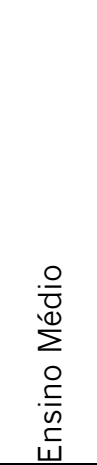 & 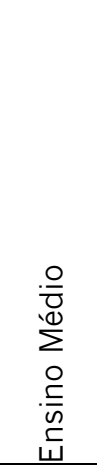 & 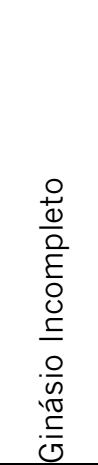 & 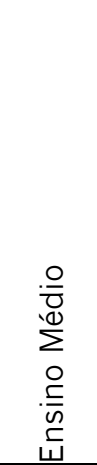 & 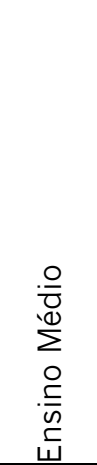 & 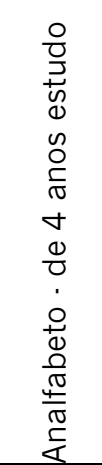 & 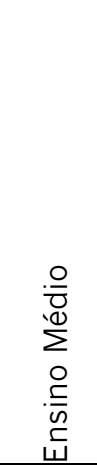 & 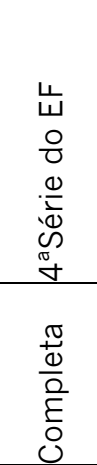 & 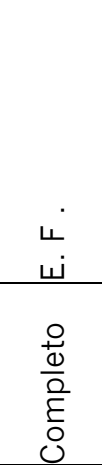 & 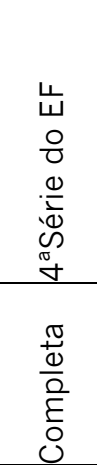 & 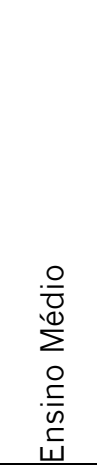 & 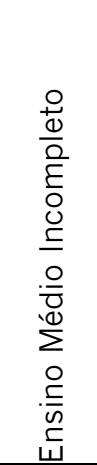 & 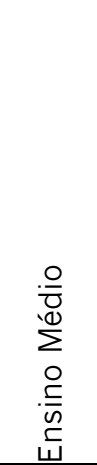 & 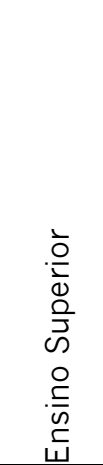 & 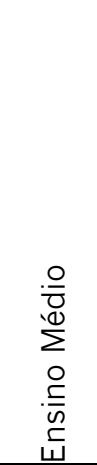 & 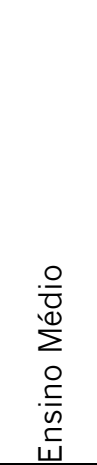 \\
\hline
\end{tabular}

Fonte: ESEB, 2002, 2006, 2010. Teste do Chi-Square: Sig 0,000 em 2002, 2006 e 2010.

\footnotetext{
${ }^{1}$ [1] Em 2006, o nível de escolaridade mais freqüente no eleitorado era o ginásio incompleto com 16,8\% do total, mas, com uma taxa muito próxima, tinha-se o grupo de eleitores com segundo grau completo com 16,6\%. Da mesma maneira, no que se refere aos partidários, a taxa de eleitores com ginásio incompleto era de $16,5 \%$ e a de colegial completo era de $16 \%$.
} 


\section{A composição da mudança}

A partir das análises de como os grupos com escolaridades distintas se comportaram no que tange à identidade partidária, foi possível entender como se deu a alteração da moda detectada anteriormente. O primeiro ponto a ser ressaltado é que, apesar da queda da identidade partidária ter acontecido em todos os segmentos de escolaridade, ela não incidiu de maneira homogênea. No segmento dos partidários com ensino superior foi possível perceber uma redução de 21,6 pontos percentuais, de 11,10 entre aqueles com ensino médio, e entre os que tinham ensino fundamental o decréscimo foi de 8,8 pontos. Ou seja, em termos percentuais, houve maior perda de eleitores partidários nos segmentos com mais escolaridade do que naquele com menos instrução, daí a moda ter sido alterada entre 2002 e 2006. De 2006 a 2010, embora se perceba um retorno em todos os segmentos, é dentro dos grupos dos mais instruídos que há uma taxa maior de resgate da identidade partidária. Ou seja, as alterações das modas estão antes relacionadas com a oscilação dos eleitores partidários com mais escolaridade do que ao movimento do outro segmento.

Ao longo de todo o período (2002/2010), contata-se que a identidade partidária sofreu um leve acréscimo entre os eleitores com baixa escolaridade (de 1,5 pontos percentuais) e um discreto decréscimo nas demais faixas (de 2,4 pontos entre aqueles com ensino médio e 2,9 entre os com ensino superior). O eleitor que demonstrou-se mais volátil no que se refere à identidade partidária no período foi o eleitor com ensino superior. 
Tabela 3 (a)

Distribuição da identidade partidária dentre as faixas de escolaridade 2002, 2006 e 2010 (\%)

\begin{tabular}{||l|c|c|c|c|c|c|c|c|c||}
\hline & \multicolumn{3}{|c|}{2002} & \multicolumn{3}{c|}{2006} & \multicolumn{3}{c||}{2010} \\
\hline Escolaridade & Sim & Não & Total & Sim & Não & Total & Sim & Não & Total \\
\hline $\begin{array}{l}\text { Ensino } \\
\text { Fundamental }\end{array}$ & 37,1 & 62,9 & 100 & 28,3 & 71,7 & 100 & 38,6 & 61,4 & 100 \\
\hline Ensino Médio & 44,4 & 55,6 & 100 & 33,3 & 66,7 & 100 & 42,0 & 58,0 & 100 \\
\hline $\begin{array}{l}\text { Ensino } \\
\text { Superior }\end{array}$ & 47,1 & 52,9 & 100 & 25,5 & 74,5 & 100 & 44,2 & 55,8 & 100 \\
\hline $\begin{array}{l}\text { Pearson Chi- } \\
\text { quadrado }\end{array}$ & $\begin{array}{c}\text { Sig. } \\
0,000\end{array}$ & & & $\begin{array}{c}\text { Sig. } \\
0,222\end{array}$ & & & $\begin{array}{c}\text { Sig. } \\
0,161\end{array}$ & & \\
\hline
\end{tabular}

Fonte: ESEB, 2002, 2006, 2010. Quanto ao teste Pearson Chi-quadrado, tem-se que apenas em 2002, foram verificadas diferenças significativas no comportamento dos eleitores que se enquadravam nas distintas faixas de escolaridade sobre as possibilidades de se identificarem com alguma legenda.

Tabela 3 (b)

Saldo da Distribuição da identidade partidária dentre as faixas de escolaridade (\%)

\begin{tabular}{||l|c|c|c||}
\hline \hline SALDO & $\mathbf{2 0 0 2 / 2 0 0 6}$ & $\mathbf{2 0 0 6 / 2 0 1 0}$ & $\mathbf{2 0 0 2 / 2 0 1 0}$ \\
\hline Escolaridade & Saldo & Saldo & Saldo \\
\hline Ensino Fundamental & $-8,8$ & 10,3 & 1,5 \\
\hline Ensino Médio & $-11,1$ & 8,7 & $-2,4$ \\
\hline Ensino Superior & $-21,6$ & 18,7 & $-2,9$ \\
\hline
\end{tabular}

Fonte: ESEB, 2002, 2006, 2010

Em 2002, o segmento que apresentava a maior concentração de petistas era aquele formado por eleitores com ensino médio $(70,9 \%)$ e ensino superior $(53,5 \%)$. De 2002 a 2006, ocorrem dois movimentos bastante díspares. No segmento de eleitores com baixa escolaridade, o petismo cresce 16,2 pontos percentuais, enquanto decresce em 33,5 pontos percentuais entre os eleitores com ensino superior.

Já de 2006 a 2010, o número de adeptos ao PT entre aqueles com ensino superior cresce em 23,6 pontos percentuais. Apesar da oscilação positiva, não se retoma o percentual de eleitores com vínculo com o PT vistos em 2002 neste 
segmento. Registra-se queda neste período do petismo entre os eleitores com ensino fundamental (de 3,4 pontos percentuais) e ensino médio (de 2,1 pontos).

No que diz respeito ao PMDB e ao PSDB, pode-se dizer que entre os eleitores com ensino médio e ensino superior, no período de 2002 a 2006, o vinculo partidário aumenta, mas o movimento reverte entre 2006 e 2010.

Tabela 4 (a)

Distribuição da identidade partidária para cada um dos quatro grandes partidos dentre as faixas de escolaridade - 2002, 2006 e 2010 (\%)

\begin{tabular}{|c|c|c|c|c|c|c|}
\hline & \multicolumn{6}{|c|}{2002} \\
\hline Escolaridade & PT & PMDB & PSDB & PFL/DEM & Outros & Total \\
\hline Ensino Fundamental & 53,5 & 15,2 & 8,5 & 7,0 & 15,8 & 100 \\
\hline Ensino Médio & 70,9 & 7,2 & 7,2 & 5,7 & 14,7 & 100 \\
\hline Ensino Superior & 68,1 & 1,4 & 20,8 & 3,5 & 9,7 & 100 \\
\hline \multirow[t]{2}{*}{ Pearson Chi-quadrado } & Sig. 0,003 & & & & & \\
\hline & \multicolumn{6}{|c|}{2006} \\
\hline Escolaridade & PT & PMDB & PSDB & PFL/DEM & Outros & Total \\
\hline Ensino Fundamental & 69,7 & 14,5 & 7,3 & 1,8 & 6,7 & 100 \\
\hline Ensino Médio & 61,9 & 13,1 & 16,7 & 2,4 & 5,9 & 100 \\
\hline Ensino Superior & 34,6 & 7,7 & 38,5 & 0,0 & 19,2 & 100 \\
\hline \multirow[t]{2}{*}{ Pearson Chi-quadrado } & Sig. 0,001 & & & & & \\
\hline & \multicolumn{6}{|c|}{2010} \\
\hline Escolaridade & PT & PMDB & PSDB & PFL/DEM & Outros & Total \\
\hline Ensino Fundamental & 66,3 & 9,2 & 13,5 & 0,5 & 10,5 & 100 \\
\hline Ensino Médio & 59,8 & 5,2 & 16,7 & 2,0 & 16,3 & 100 \\
\hline Ensino Superior & 58,2 & 2,7 & 13,6 & 2,7 & 22,8 & 100 \\
\hline Pearson Chi-quadrado & Sig. 0,131 & & & & & \\
\hline
\end{tabular}

Fonte: ESEB, 2002, 2006, 2010. Quanto ao teste Pearson Chi-quadrado, verifica-se que em 2002 e em 2006 havia diferenças significativas entre os eleitores que se enquadravam nas distintas faixas de escolaridade quanto às possibilidades de se identificarem mais ou menos com determinada legenda (Sig. 0,003 e Sig. 0,001, respectivamente). No entanto, em 2010, tal tendência não se repete (Sig.0,131). 
VEIGA, L. F. O partidarismo no Brasil (2002/2010)

Tabela 4 (b)

Saldo da Distribuição da identidade partidária para cada um dos quatro grandes partidos dentre as faixas de escolaridade - 2002, 2006 e 2010 (\%)

\begin{tabular}{||l|c|c|c|c|c|c||}
\hline & \multicolumn{3}{|c|}{ SALDO PT } & $\begin{array}{c}\text { SALDO } \\
\text { PMDB }\end{array}$ & $\begin{array}{c}\text { SALDO } \\
\text { PSDB }\end{array}$ & $\begin{array}{c}\text { SALDO } \\
\text { PFL/DEM }\end{array}$ \\
\hline & $\begin{array}{c}2002 / \\
2006\end{array}$ & $\begin{array}{c}2006 / \\
2010\end{array}$ & $\begin{array}{c}2002 / \\
2010\end{array}$ & $\begin{array}{c}2002 / \\
2010\end{array}$ & $\begin{array}{c}2002 / \\
2010\end{array}$ & $\begin{array}{c}2002 / \\
2010\end{array}$ \\
\hline $\begin{array}{l}\text { Ensino } \\
\text { fundamental }\end{array}$ & 16,2 & $-3,4$ & 12,8 & $-6,0$ & 5,0 & $-6,5$ \\
\hline Ensino médio & $-9,0$ & $-2,1$ & $-11,1$ & $-2,0$ & 9,5 & $-3,7$ \\
\hline Ensino superior & $-33,5$ & 23,6 & $-9,9$ & 1,3 & $-7,2$ & $-0,8$ \\
\hline
\end{tabular}

Fonte: ESEB, 2002, 2006, 2010

Ao final do período, de 2002 a 2010, observa-se que a identificação com o PT entre os eleitores com ensino superior caiu em 9,9 pontos percentuais e 11,1 pontos entre os eleitores com ensino médio. Já entre os eleitores com ensino fundamental, ela cresceu 12,8 pontos.

Ao longo de 2002 a 2010, são mais sensíveis as perdas de vínculo com o PMDB no grupo eleitores com ensino fundamental (de 6 pontos percentuais), mas a curva descendente também é visível dentre os eleitores de ensino médio (menos 2 pontos). Quanto ao PSDB, entre os eleitores com ensino superior registrou-se a maior perda de partidários, de 7,2 pontos percentuais. Nos diversos segmentos de escolaridade, registrou-se a perda de identidade com o PFL/DEM.

\section{Regiões. A evolução do perfil}

De 2002 a 2006, a taxa de identidade partidária cresce em 9 pontos percentuais no Sul do país, em 5,4 pontos no Norte/Centro Oeste, e de maneira menos acentuada, em 0,9 pontos, no Nordeste, e decresce apenas na região Sudeste, em 12,9 pontos. De 2006 a 2010, o vínculo partidário continua a crescer no Nordeste (3,1 pontos percentuais); o crescimento também é observado na região Sudeste (de 3,6 pontos), de forma a atenuar a queda identificada no período anterior, mantém-se no Norte/Centro Oeste (acréscimo de 0,1 ponto) e recua no Sul no país (em 6,8 pontos). 
De 2002 a 2006, o petismo cresce 10 pontos percentuais no Nordeste e 6 pontos percentuais no Norte/Centro Oeste, mantém-se com os mesmos percentuais no Sul e decresce em 16 pontos no Sudeste. De 2006 a 2010, o vínculo com o PT permanece praticamente constante no Nordeste (decréscimo de 0,1 pontos percentuais), sofre leve redução no Norte/Centro Oeste (de 1,1 pontos) e Sul (de 1,6 pontos), e aumenta em 2,8 pontos no Sudeste, diminuindo a perda do período anterior. A expansão do petismo no Nordeste é a continuidade de um movimento identificado por Venturi:

Inicialmente, em 1989, mais de três quintos dos "petistas" (62\%) estavam no Sudeste (que abriga cerca de $44 \%$ do eleitorado) e apenas $14 \%$ no Nordeste (com $28 \%$ dos eleitores) - desequilíbrio que seria atenuado nos anos 1990, mas que estará presente até as eleições de 2002. Só em abril de 2005, pré-crise, os "petistas" apresentaram pela primeira vez proporções que se aproximam da distribuição do universo eleitoral: $43 \%$ estavam no Sudeste, $31 \%$ no Nordeste, $14 \%$ no Sul e $12 \%$ no Norte/Centro-Oeste. Mas, ao se recuperarem da crise, um ano depois, o desbalanço na distribuição dos "petistas" reapareceria,só que agora com o Sudeste abaixo de sua proporção no eleitorado (apenas 37\%) e o Nordeste acima (34\%). (VENTURI, 2010, p. 207)

Enquanto o vínculo partidário com o PT avança no Nordeste, o elo com o PMDB é reduzido em 18 pontos na região no período de 2002 a 2006. Há um leve decréscimo de identidade partidária com o PMDB também no Sudeste no mesmo período com perda de dois pontos. No Sul, registra-se acentuado crescimento de adesão ao partido, com aumento de 15 pontos percentuais, e cresce também a identidade partidária nas regiões Norte e Centro Oeste em 5 pontos. De 2006 a 2010, o partid o recupera a adesão na região Nordeste, quando sobe 14,8 pontos percentuais; cresce também o vínculo no Norte e Centro Oeste, acumulando a soma de 10,2 pontos em aumento da identidade partidária no período de 2002 a 2010. Há perdas de partidários no Sudeste, e de maneira mais acentuada, no Sul.

Apesar das oscilações em 2006, registra-se a tendência de estabilidade na distribuição de identidade partidária com o DEM/PFL entre as regiões, prevalecendo ainda o vínculo com o Nordeste do país. No caso do PSDB, há uma queda nas regiões Nordeste e Sudeste e um crescimento de identidade partidária nas regiões Sul e Norte/Centro Oeste no período de 2002 a 2010. 
Tabela 5

Distribuição da identidade partidária por região do Brasil 2002, 2006 e 2010 (\%)

\begin{tabular}{|c|c|c|c|c|}
\hline PARTIDO & REGIÃO & 2002 & 2006 & 2010 \\
\hline \multirow[t]{5}{*}{ Partidários } & Nordeste & 24,8 & 25,7 & 28,8 \\
\hline & Norte/Centro-Oeste & 8,7 & 14,1 & 14,3 \\
\hline & Sudeste & 54,2 & 41,3 & 44,9 \\
\hline & Sul & 9,8 & 18,8 & 12 \\
\hline & Total & 100 & 100 & 100 \\
\hline \multirow[t]{5}{*}{ Eleitores } & Nordeste & 24,7 & 26,9 & 27 \\
\hline & Norte/Centro-Oeste & 9,2 & 12,4 & 14,4 \\
\hline & Sudeste & 53,1 & 45,2 & 43,6 \\
\hline & Sul & 12,9 & 15,4 & 15 \\
\hline & Total & 100 & 100 & 100 \\
\hline \multirow[t]{5}{*}{ PT } & Nordeste & 22 & 32 & 31,9 \\
\hline & Norte/Centro-Oeste & 8 & 14 & 12,9 \\
\hline & Sudeste & 58 & 42 & 44,8 \\
\hline & Sul & 12 & 12 & 10,4 \\
\hline & Total & 100 & 100 & 100 \\
\hline \multirow[t]{5}{*}{ PMDB } & Nordeste & 31 & 13 & 27,8 \\
\hline & Norte/Centro-Oeste & 12 & 17 & 22,2 \\
\hline & Sudeste & 38 & 36 & 31,5 \\
\hline & Sul & 19 & 34 & 18,5 \\
\hline & Total & 100 & 100 & 100 \\
\hline \multirow[t]{5}{*}{ DEM/PFL } & Nordeste & 46 & 94 & 50 \\
\hline & Norte/Centro-Oeste & 9 & 0 & 0 \\
\hline & Sudeste & 33 & 0 & 30 \\
\hline & Sul & 12 & 6 & 20 \\
\hline & Total & 100 & 100 & 100 \\
\hline \multirow[t]{5}{*}{ PSDB } & Nordeste & 23 & 15 & 16,8 \\
\hline & Norte/Centro-Oeste & 9 & 11 & 16,8 \\
\hline & Sudeste & 61 & 52 & 51 \\
\hline & Sul & 7 & 23 & 15 \\
\hline & Total & 100 & 100 & 100 \\
\hline
\end{tabular}

Fonte: ESEB, 2002, 2006 e 2010. Teste de independência de médias: Sig 0,001 em 2002 e Sig 0,000 em 2006 e 2010. Os resultados dos testes apontam que há diferenças significativas quanto à distribuição da identidade partidária entre as diversas legendas e as regiões. No entanto, não podemos afirmar se a diferença é significativa entre todos ou apenas entre um partido e os demais. 


\section{A composição da mudança}

Em 2002, havia mais concentração de eleitores partidários no Sudeste $(41,7 \%)$ e no Nordeste $(41,1 \%)$. Mas de 2002 a 2006, quando ocorre queda do vínculo partidário em todas as regiões, o decréscimo é mais sentido nas mesmas, tendo recuado 15,4 pontos percentuais no Sudeste e 11,8 no Nordeste.

Já de 2006 a 2010, percebe-se o acréscimo do vínculo partidário em meio aos eleitores das diversas regiões, exceção para o grupo do Sul do país, onde a identidade partidária continua a decrescer, em 4,9 pontos percentuais. Dentre os eleitores da região Sudeste, o acréscimo de 15 pontos percentuais fez quase neutralizar a queda da identidade partidária sentida no período anterior. E no caso do Nordeste, nota-se o aumento da identidade partidária em 14,4 pontos percentuais, acumulando nos dois períodos o avanço de 2,6 pontos.

Ao longo de todo o período (2002/2010), observa-se leve aumento da incidência de eleitores partidários nas regiões Norte/Centro Oeste e Nordeste - 2,3 e 2,6 pontos percentuais respectivamente; uma queda mínima, de 0,4 pontos percentuais, em meio aos eleitores do Sudeste do país, e o decréscimo de 5,90 pontos dentre os eleitores do Sul.

\section{Tabela 6 (a)}

Distribuição da identidade partidária em meio às regiões do Brasil 2002, 2006 e 2010 (\%)

\begin{tabular}{||l|c|c|c|c|c|c|c|c|c||}
\hline & \multicolumn{3}{|c|}{2002} & \multicolumn{3}{c|}{2006} & \multicolumn{3}{c||}{2010} \\
\hline $\begin{array}{l}\text { Região do } \\
\text { País }\end{array}$ & Sim & Não & Total & Sim & Não & Total & Sim & Não & Total \\
\hline $\begin{array}{l}\text { Norte/ } \\
\text { Centro-Oeste }\end{array}$ & 37,8 & 62,2 & 100 & 31,5 & 68,5 & 100 & 40,1 & 59,9 & 100 \\
\hline Nordeste & 41,1 & 58,9 & 100 & 29,3 & 70,7 & 100 & 43,7 & 56,3 & 100 \\
\hline Sudeste & 41,7 & 58,3 & 100 & 26,3 & 73,7 & 100 & 41,3 & 58,7 & 100 \\
\hline Sul & 38,1 & 61,9 & 100 & 37,1 & 62,9 & 100 & 32,2 & 67,8 & 100 \\
\hline $\begin{array}{l}\text { Pearson Chi- } \\
\text { quadrado }\end{array}$ & $\begin{array}{c}\text { Sig } \\
0,527\end{array}$ & & & $\begin{array}{c}\text { Sig } \\
0,098\end{array}$ & & & $\begin{array}{c}\text { Sig. } \\
0,013\end{array}$ & & \\
\hline \hline
\end{tabular}

Fonte: ESEB, 2002, 2006, 2010. Quanto ao teste do Pearson Chi-quadrado, apenas em 2010 foi possível verificar diferenças entre os eleitores das distintas regiões no que tange à identidade partidária (Sig. 0,013). Ou seja, apenas em 2010, a região de moradia passa a ser um diferencial sobre ter ou não ter identidade partidária. 
VEIGA, L. F. O partidarismo no Brasil (2002/2010)

Tabela 6 (b)

Saldo da distribuição da identidade partidária por região do Brasil (\%)

\begin{tabular}{||l|c|c|c||}
\hline \hline 2002, 2006 E 2010 (\%). & $\mathbf{2 0 0 2 / 2 0 0 6}$ & $\mathbf{2 0 0 6 / 2 0 1 0}$ & $\mathbf{2 0 0 2 / 2 0 1 0}$ \\
\hline Região do País & Saldo & Saldo & Saldo \\
\hline Norte/ Centro-Oeste & $-6,3$ & 8,6 & 2,3 \\
\hline Nordeste & $-11,8$ & 14,4 & 2,6 \\
\hline Sudeste & $-15,4$ & 15,0 & $-0,4$ \\
\hline Sul & $-1,0$ & $-4,9$ & $-5,9$ \\
\hline
\end{tabular}

Fonte: ESEB, 2002, 2006, 2010

Em 2002, a região na qual se notava maior presença de eleitores com vínculo com o PT era o Sudeste (65,9\%), seguido do Sul (62,3\%); entre 2006 e 2010, o número de petistas dentre os eleitores do Sul decresceu em 21,9 pontos percentuais. No sentido inverso, a presença do laço com o PT em meio ao eleitorado do Nordeste cresceu 24,6 pontos percentuais. O aumento do petismo também ocorreu nas regiões Norte e Centro Oeste, em 6,7 pontos. Em 2006, o Nordeste era a região que contava com a maior concentração de petistas, 80,3\% dentre aqueles com identidade partidária. Ao final do período, de 2002 a 2010, registra-se que a identificação com o PT dentre os eleitores do Nordeste cresceu em $14,9 \%$, e ainda teve um leve aumento no interior do eleitorado do Norte e Centro Oeste de 1,5 pontos percentual. Em meio aos eleitores do Sudeste e do Sul, a perda foi de 3,1 pontos e oito pontos percentuais, respectivamente.

No nicho que PT mais viu crescer o seu vínculo com o eleitor é aquele em que o PMDB e PFL/DEM mais perderam eleitores identificados - 6,4 e 8,7 pontos percentuais, respectivamente, ou seja, no Nordeste. 
Tabela 7 (a)

Distribuição da identidade partidária por partido

e por região - 2002, 2006 e 2010 (\%)

\begin{tabular}{|c|c|c|c|c|c|c|}
\hline & \multicolumn{6}{|c|}{2002} \\
\hline Região do País & PT & PMDB & PSDB & PFL/DEM & Outros & Total \\
\hline Norte/ Centro-Oeste & 54,8 & 13,1 & 6,5 & 6,0 & 19,6 & 100 \\
\hline Nordeste & 55,7 & 13,2 & 9,2 & 11,0 & 10,9 & 100 \\
\hline Sudeste & 65,9 & 7,3 & 11,0 & 3,5 & 12,3 & 100 \\
\hline Sul & 62,3 & 15,8 & 6,1 & 6,1 & 9,7 & 100 \\
\hline \multirow[t]{2}{*}{ Pearson Chi-quadrado } & Sig 0,004 & & & & & \\
\hline & \multicolumn{6}{|c|}{2006} \\
\hline Região do País & PT & PMDB & PSDB & PFL/DEM & Outros & Total \\
\hline Norte/ Centro-Oeste & 61,5 & 15,4 & 10,3 & 0,0 & 12,8 & 100 \\
\hline Nordeste & 80,3 & 7,0 & 7,0 & 5,6 & 0,1 & 100 \\
\hline Sudeste & 66,7 & 11,7 & 17,1 & 0,0 & 4,5 & 100 \\
\hline Sul & 40,4 & 23,1 & 15,4 & 0,0 & 21,1 & 100 \\
\hline \multirow[t]{2}{*}{ Pearson Chi-quadrado } & Sig. 0,000 & & & & & \\
\hline & \multicolumn{6}{|c|}{2010} \\
\hline Região do País & PT & PMDB & PSDB & PFL/DEM & Outros & Total \\
\hline Norte/ Centro-Oeste & 56,3 & 10,7 & 17,0 & 0,0 & 16,0 & 100 \\
\hline Nordeste & 70,6 & 6,8 & 8,6 & 2,3 & 11,7 & 100 \\
\hline Sudeste & 62,8 & 4,9 & 16,6 & 0,9 & 14,8 & 100 \\
\hline Sul & 54,3 & 10,6 & 18,1 & 2,1 & 14,9 & 100 \\
\hline Pearson Chi-quadrado & Sig. 0,052 & & & & & \\
\hline
\end{tabular}

Fonte: ESEB, 2002, 2006, 2010. Quanto ao teste Pearson Chi-quadrado, verifica-se que em 2002 e em 2006 havia diferenças entre os eleitores que se enquadravam nas distintas regiões no que tange às possibilidades de se identificarem mais ou menos com determinada legenda (Sig. 0,004 e Sig. 0,000, respectivamente). No entanto, em 2010, não foi possível identificar tal diferença entre os eleitores de regiões distintas (Sig.0,052). 
Tabela 7 (b)

Distribuição da identidade partidária por partido

dentre as regiões - 2002, 2006 e 2010

\begin{tabular}{|c|c|c|c|c|c|c|c|}
\hline & \multicolumn{3}{|c|}{ Saldo PT } & Saldo & Saldo & Saldo & \\
\hline Região do País & $\begin{array}{l}20021 \\
2006\end{array}$ & $\begin{array}{l}2006 / \\
2010\end{array}$ & $\begin{array}{l}2002 / \\
2010\end{array}$ & $\begin{array}{l}2002 / \\
2010\end{array}$ & $\begin{array}{l}2002 / \\
2010\end{array}$ & $\begin{array}{l}2002 / \\
2010\end{array}$ & Outros \\
\hline $\begin{array}{l}\text { Norte/ } \\
\text { Centro-Oeste }\end{array}$ & 6,7 & $-5,2$ & 1,5 & $-2,4$ & 10,5 & .6 & $-0,036$ \\
\hline Nordeste & 24,6 & $\begin{array}{l}-9,7 \\
\end{array}$ & 14,9 & $-6,4$ & $-0,6$ & -9 & 0,008 \\
\hline Sudeste & 0,8 & $.3,9$ & $-3,1$ & $-2,4$ & 5,6 & -3 & 0,025 \\
\hline Sul & $-21,9$ & 13,9 & $-8,0$ & $-5,2$ & 12,0 & .4 & 0,052 \\
\hline
\end{tabular}

Fonte: ESEB, 2002, 2006, 2010

\section{Ideologia. A evolução do perfil}

Em 2002 e 2006 o eleitor em geral tendia a se autolocalizar mais à direita na escala ideológica do que o eleitor com identidade partidária, uma tendência que se altera em 2010. Os eleitores partidários caminharam para a direita com passos mais largos do que o total do eleitorado neste período de oito anos. Situação semelhante pode ser encontrada entre os eleitores com vínculo petista, que deixaram de definir-se como de centro esquerda (média 4,7) em 2002, para se autolocalizarem como centro-direita (média 5,98) em 2010. 0 mesmo movimento não foi registrado entre os partidários das demais legendas, que oscilaram em avanços à esquerda na escala ideológica em 2006 e depois à direita, em 2010. 
Tabela 8

Autolocalização ideológica do eleitorado, dos eleitores partidários e dos partidários com PT, PMDB, DEM/PFL e PSDB (moda) - 2002, 2006 e 2010 (\%)

\begin{tabular}{||l|l|c|c|c||}
\hline & & $\mathbf{2 0 0 2}$ & $\mathbf{2 0 0 6}$ & $\mathbf{2 0 1 0}$ \\
\hline Eleitores & Média & 6,03 & 6,04 & 6,35 \\
\hline & Mediana & 6 & 5 & 7 \\
\hline & Desvio Padrão & 3,34 & 2,78 & 3,19 \\
\hline & Média & 5,55 & 5,71 & 6,44 \\
\hline & Mediana & 5 & 5 & 7 \\
\hline PT & Desvio Padrão & 3,7 & 3,16 & 3,41 \\
\hline & Média & 4,7 & 5,5 & 5,98 \\
\hline & Mediana & 5 & 5 & 7 \\
\hline PMDB & Desvio Padrão & 3,6 & 3,4 & 3,54 \\
\hline & Média & 8,3 & 6,3 & 7,7 \\
\hline & Mediana & 10 & 5,0 & 9,0 \\
\hline DEM/PFL & Desvio Padrão & 2,7 & 2,3 & 2,78 \\
\hline & Média & 6,1 & 8,5 & 5,0 \\
\hline & Mediana & 8,0 & 10 & 5,0 \\
\hline PSDB & Desvio Padrão & 3,9 & 3,4 & 4,0 \\
\hline & Média & 6,5 & 5,7 & 8,02 \\
\hline & Mediana & 8 & 6 & 9 \\
\hline & Desvio Padrão & 3,3 & 3,4 & 2,59 \\
\hline
\end{tabular}

Fonte: ESEB, 2002, 2006 e 2010.

Escala: Esquerda (0) a Direita (10)

\section{A composição da mudança}

Em 2002, os segmentos ideológicos que mais continham eleitores com identidade partidária eram os de esquerda $(66,1 \%)$ e os de centro-esquerda (49,1\%). De 2002 a 2006, houve queda do vínculo partidário dentre os diferentes agrupamentos ideológicas, com exceção para aquele de centro-direita.

De 2006 a 2010, observa-se o acréscimo do vínculo partidário em meio aos eleitores de todos agrupamentos ideológicos com exceção para o de centroesquerda, mas tal acréscimo não ocorreu de maneira homogênea, tendo os segmentos de centro-direita (10,7 pontos percentuais) e direita $(13,1)$ angariado mais partidários do que os de esquerda $(1,9)$ e centro (5). Em 2010, os segmentos 
de esquerda e de centro-esquerda continuam concentrando mais eleitores partidários do que os demais grupos.

Ao longo de todo o período analisado, registra-se o aumento da incidência de eleitores partidários em meio aos eleitores de centro-direita com 13,9 pontos percentuais e dentre o segmento de direita, com 6,4 pontos percentuais. Observa-se ainda, a queda da identidade partidária em meio aos eleitores de centro (4,1 pontos percentuais), centro-esquerda $(6,8)$ e esquerda $(4,2)$. Ou seja, os eleitores com identidade partidária no interior dos segmentos de esquerda, centro-esquerda e centro foram reduzidos em termos percentuais ao longo dos oito anos, enquanto a centro-direita e direita passaram a contar com mais eleitores partidários.

Tabela 9 (a)

Distribuição da identidade partidária dentre os segmentos ideológicos (autolocalização) 2002, 2006 e 2010 (\%)

\begin{tabular}{||l|c|c|c|c|c|c|c|c|c||}
\hline & \multicolumn{3}{|c|}{2002} & \multicolumn{3}{c|}{2006} & \multicolumn{3}{c||}{2010} \\
\hline Ideologia & Sim & Não & Total & Sim & Não & Total & Sim & Não & Total \\
\hline Esquerda & 66,1 & 33,9 & 100 & 60,0 & 40,0 & 100 & 61,9 & 38,1 & 100 \\
\hline $\begin{array}{l}\text { Centro } \\
\text { Esquerda }\end{array}$ & 49,1 & 50,9 & 100 & 45,7 & 54,3 & 100 & 42,3 & 57,7 & 100 \\
\hline Centro & 36,5 & 63,5 & 100 & 27,4 & 72,6 & 100 & 32,4 & 67,6 & 100 \\
\hline $\begin{array}{l}\text { Centro } \\
\text { Direita }\end{array}$ & 29,2 & 70,8 & 100 & 32,4 & 67,6 & 100 & 43,1 & 56,9 & 100 \\
\hline Direita & 45,0 & 55,0 & 100 & 38,3 & 61,7 & 100 & 51,4 & 48,6 & 100 \\
\hline $\begin{array}{l}\text { Pearson } \\
\text { Chi- } \\
\text { quadrado }\end{array}$ & $\begin{array}{c}\text { Sig. } \\
0,000\end{array}$ & & & $\begin{array}{c}\text { Sig. } \\
0,000\end{array}$ & & & $\begin{array}{c}\text { Sig. } \\
0,000\end{array}$ & & \\
\hline
\end{tabular}

Fonte: ESEB, 2002, 2006 e 2010 Categorias de auto-localização ideológica: de 0 a 2 (esquerda), de 3 a 4 (centro esquerda), 5 (centro), de 6 a 7 (centro direita), de 8 a 10 (direita). Quanto ao teste do Pearson Chiquadrado, foi possível verificar que a postura ideológica do eleitor é significativa no que se refere a ele ter ou não ter identidade partidária em todo o período de 2002 a 2010. 
Tabela 9 (b)

Saldo da Distribuição da identidade partidária dentre os segmentos ideológicos (autolocalização) (\%)

\begin{tabular}{|c|c|c|c|}
\hline & $2002 / 2006$ & $2006 / 2010$ & $2002 / 2010$ \\
\hline Ideologia & Saldo & Saldo & Saldo \\
\hline Esquerda & $-6,10$ & 1,90 & $.4,20$ \\
\hline Centro Esquerda & $-3,40$ & $\cdot 3,40$ & $-6,80$ \\
\hline Centro & $-9,10$ & 5,00 & $-4,10$ \\
\hline Centro Direita & 3,20 & 10,70 & 13,90 \\
\hline Direita & $.6,70$ & 13,10 & 6,40 \\
\hline
\end{tabular}

Fonte: ESEB, 2002, 2006 e 2010

Em 2002, os segmentos de eleitores de esquerda (75\%), centro-esquerda (76\%) e centro $(71,9 \%)$ apresentavam maior concentração de petistas. Com a queda do vínculo com o PT de 2002 a 2006, a redução pode ser notada no interior dos diferentes segmentos ideológicos, com exceção do grupo que se autolocalizava à direita. Neste nicho, o número de petistas subiu, no período, 15,3 pontos percentuais. A maior queda deu-se no agrupamento de centro do espectro ideológico, com a redução de 19 pontos percentuais de petismo. No momento posterior, com a retomada por parte do eleitorado da identidade petista, não se verifica qualquer movimento de retorno neste segmento de esquerda. No eleitorado do centro, o déficit acumulado ao longo dos oito anos é de 19,7 pontos percentuais. Entre os partidários do grupo de esquerda, a queda também mostrou-se contínua, sem reversão. Mas, no sentido oposto, registra-se o crescimento da identidade com o PT no decorrer do período nos segmentos de centro-esquerda (6,9 pontos percentuais) e de direita (14,2 pontos percentuais).

Enquanto o petismo cresceu dentre os eleitores de centro-esquerda, foi neste grupo que o PSDB perdeu partidários. Em todos os demais, o partido tucano conseguiu aumentar o grau de partidarismo. PMDB e PFL/Dem perderam partidários nos diferentes segmentos ideológicos, mas a redução foi mais perceptível entre os eleitores de direita. 
Tabela 10 (a)

Distribuição da identidade partidária para os partidos dentre os segmentos ideológicos (autolocalização) - 2002, 2006 e 2010

\begin{tabular}{|c|c|c|c|c|c|c|}
\hline & \multicolumn{6}{|c|}{2002} \\
\hline Ideologia & PT & PMDB & PSDB & PFL/Dem & Outros & Total \\
\hline Esquerda & 75,4 & 2,6 & 4,4 & 7,0 & 10,6 & 100 \\
\hline Centro-Esquerda & 76,0 & 0,0 & 18,0 & 0,0 & 6,0 & 100 \\
\hline Centro & 71,9 & 6,3 & 7,8 & 4,7 & 9,3 & 100 \\
\hline Centro-Direita & 63,6 & 12,1 & 12,1 & 3,0 & 9,2 & 100 \\
\hline Direita & 44,7 & 20,7 & 14,0 & 8,4 & 12,2 & 100 \\
\hline \multirow[t]{2}{*}{ Pearson Chi-quadrado } & Sig 0,079 & & & & & \\
\hline & \multicolumn{6}{|c|}{2006} \\
\hline Ideologia & PT & PMDB & PSDB & PFL/Dem & Outros & Total \\
\hline Esquerda & 72,50 & 2,50 & 12,50 & 0,00 & 12,50 & 100 \\
\hline Centro-Esquerda & 61,90 & 19,00 & 9,50 & 4,80 & 4,80 & 100 \\
\hline Centro & 52,90 & 27,50 & 9,80 & 0,00 & 9,80 & 100 \\
\hline Centro-Direita & 47,80 & 13,00 & 17,40 & 0,00 & 21,80 & 100 \\
\hline Direita & 60,00 & 14,70 & 14,70 & 2,70 & 7,90 & 100 \\
\hline \multirow[t]{2}{*}{ Pearson Chi-quadrado } & Sig. 0,055 & & & & & \\
\hline & \multicolumn{6}{|c|}{2010} \\
\hline Ideologia & PT & PMDB & PSDB & PFL/Dem & Outros & Total \\
\hline Esquerda & 67,70 & 2,10 & 8,30 & 4,20 & 17,70 & 100 \\
\hline Centro-Esquerda & 82,90 & 0,00 & 0,00 & 0,00 & 17,10 & 100 \\
\hline Centro & 52,20 & 7,20 & 15,90 & 1,40 & 23,30 & 100 \\
\hline Centro-Direita & 52,50 & 8,50 & 15,30 & 1,70 & 22,00 & 100 \\
\hline Direita & 58,90 & 9,80 & 21,10 & 1,60 & 8,60 & 100 \\
\hline Pearson Chi-quadrado & Sig. 0,001 & & & & & \\
\hline
\end{tabular}

Fonte: ESEB 2002,2006 e 2010. Quanto ao teste Pearson Chi-quadrado, verifica-se que apenas em 2010 a ideologia dos eleitores partidários foi significativa que tange à qual partido se identificar. 
Tabela 10 (b)

Distribuição da identidade partidária para os partidos dentre os segmentos ideológicos (autolocalização) - 2002, 2006 e 2010

\begin{tabular}{||l|c|c|c|c|c|c||}
\hline & \multicolumn{3}{|c|}{ SALDO PT } & $\begin{array}{c}\text { SALDO } \\
\text { PMDB }\end{array}$ & $\begin{array}{c}\text { SALDO } \\
\text { PSDB }\end{array}$ & $\begin{array}{c}\text { SALDO } \\
\text { PFL/DEM }\end{array}$ \\
\hline Ideologia & $2002 /$ & $2006 /$ & $2002 /$ & $2002 /$ & $2002 /$ & $2002 /$ \\
& 2006 & 2010 & 2010 & 2010 & 2010 & 2010 \\
\hline Esquerda & $-2,90$ & $-4,80$ & $-7,70$ & $-0,50$ & 3,90 & $-2,80$ \\
\hline Centro-Esquerda & $-14,10$ & 21,00 & 6,90 & 0,00 & $-18,00$ & 0,00 \\
\hline Centro & $-19,00$ & $-0,70$ & $-19,70$ & 0,90 & 8,10 & $-3,30$ \\
\hline Centro-Direita & $-15,80$ & 4,70 & $-11,10$ & $-3,60$ & 3,20 & $-1,30$ \\
\hline Direita & 15,30 & $-1,10$ & 14,20 & $-10,90$ & 7,10 & $-6,80$ \\
\hline
\end{tabular}

Fonte: ESEB 2002, 2006 e 2010.

\section{Considerações finais}

O objetivo deste trabalho foi apresentar a evolução do partidarismo e do petismo no Brasil no período de 2002 a 2010, tendo como base os surveys póseleitorais da coleção ESEB, realizados em 2002, 2006 e 2010. O primeiro objetivo específico foi mensurar as variações do partidarismo no período. Neste caso, o foco esteve no partidarismo e nos vínculos com os quatro maiores partidos brasileiros: PT, PMDB, PSDB e DEM. A relevância do PT nesta análise deve-se à sua importância destacada para o partidarismo no país. Também buscamos identificar as mudanças nos perfis dos partidários nos três momentos analisados, onde o interesse maior foi em acompanhar as variações nas características de escolaridade, região e ideologia. Finalmente procura-se entender como tal mudança havia se constituído. Apresento a seguir uma discussão sobre os principais achados.

O partidarismo no país caiu no período de 2002 a 2006 de 39\% para 28\%; e atingiu o patamar mais baixo verificado desde 1987. O eleitorado estava sob o efeito das denúncias do esquema de corrupção - conhecido como Mensalão - que envolvia o PT, outros partidos da base aliada e o Governo Lula. Por sua vez, de 2006 a 2010, o partidarismo subiu 11,2 pontos percentuais, voltando a um estágio muito próximo ao ponto de partida em 2002, e retomando as taxas usuais presentes ao longo do período da Nova República.

A legenda que mais perdeu adeptos com a queda do partidarismo foi o PT, com a taxa de identidade reduzida em 5 pontos percentuais. Nenhum dos grandes 
partidos se beneficiou de tal perda do petismo. Com o movimento da retomada foi novamente o PT que se destacou e subiu 6,5 pontos percentuais, atingindo $24,5 \%$ de identidade junto ao eleitorado brasileiro. É instigante pensar na força demonstrada por este partido, que afastou sem afugentar seus adeptos, e conseguiu reavê-los em um curto período de tempo.

Analisamos o partidarismo segundo as características de escolaridade, região e ideologia. Com relação a escolaridade, de 2002 a 2006, observou-se sua redução entre os eleitores com identidade partidária e aqueles vinculados com alguma das quatro legendas sob análise, com exceção do PMDB. De 2006 para 2010, ocorreu o aumento do grau de instrução no eleitorado, nos partidários e naqueles que apresentam vínculo com o PT e o DEM e a manutenção da escolaridade entre os vinculados ao PSDB, estabelecendo como padrão de eleitor . partidário ou não - aquele com ensino médio, exceção, novamente, apenas para o PMDB. Com relação à constituição da mudança geral, vimos que as alterações das modas no período de 2002 a 2010 estão antes relacionadas com a oscilação mais acentuada dos eleitores partidários com mais escolaridade do que ao movimento do eleitorado de ensino fundamental.

Com relação à constituição da mudança do perfil do petista em específico verificou-se no decorrer de 2002 a 2010 o crescimento 12,8 pontos percentuais da adesão ao partido dentro do segmento de eleitores com ensino fundamental e as perdas de 9,9 pontos percentuais dente os votantes de ensino superior e de 11,1 dentre os votantes de ensino médio.

Sobre a distribuição geográfica, de 2002 a 2010 o partidarismo cresceu no Nordeste, Norte/Centro Oeste, Sul e decresceu no Sudeste. O petismo subiu de maneira acentuada no Nordeste de 2002 a 2006 e se manteve até 2010, sendo que um movimento parecido, apenas mais tênue, ocorreu no Norte/Centro Oeste. De 2002 a 2006, o vínculo com o PT foi reduzido no Sudeste e recuperou-se um pouco de 2006 a 2010. No caso do Sul, houve pequena perda do vínculo, nesse período.

Sobre o petismo em específico, ao final do período de 2002 a 2010, ele cresceu em meio ao grupo de eleitores do Nordeste chegando a 70,6\% em 2010, e teve ainda um leve aumento no interior do eleitorado do Norte e Centro Oeste sua perda ocorreu em meio aos eleitores do Sudeste e do Sul.

Sobre a caracterização ideológica do partidarismo, observou-se que, ao longo de todo o período (2002/2010), os percentuais de eleitores com identidade partidária no interior dos segmentos de esquerda, centro-esquerda e centro foram reduzidos, enquanto os grupos com ideologia de centro direita e direita passaram a contar com mais eleitores partidários no aumento da média na escala ideológica do perfil do partidário. 
Para os petistas, com a queda do vinculo com o PT de 2002 a 2006, a redução pode ser notada no interior dos diferentes segmentos ideológicos, com exceção do grupo que se autolocalizava à direita. Neste nicho, o número de petista subiu no período em 15,3 pontos percentuais. A maior queda se deu no agrupamento de centro do espectro ideológico, com a redução de 19 pontos percentuais de petismo. No período posterior de 2006 a 2010, com a retomada da identidade partidária com o PT, não houve qualquer movimento de retorno no segmento de esquerda, no qual a adesão caiu nos dois períodos. No eleitorado do centro, e de direita houve déficits acumulados ao longo dos oito anos. No sentido oposto, registrou-se o crescimento da identidade com o PT no decorrer do período nos segmentos de centro-esquerda e de direita. Tem-se aí como constituiu-sek a mudança na média ideológica entre os petistas no período.

Este trabalho responde algumas dúvidas e sugere outras. Os achados suscitam outros questionamentos que devem motivar outras pesquisas. Por exemplo, o que explica o resgate da identidade partidária no período de 2006 a 2010, de maneira tão rápida, em todos os segmentos de eleitores, mas de maneira mais intensa entre aqueles de ensino superior? Por que após cair 33,5 pontos percentuais a taxa de petismo em meio aos eleitores com ensino superior, em apenas quatro anos, nos quatro anos seguintes, tal adesão cresce em 23,6\%? Mas existe outro questionamento que perpassa todos os números que foram vistos acima: De que "âncora política", para usar a expressão de Dalton e Wattenberg, estamos tratando nestes oito anos em foco?

\section{Referências bibliográficas:}

CAMPBELL, A.; CONVERSE, P. E.; MILLER, W.; STUKES, D. E. 1960. The american voter. NY: Wiley. 1960.

DALTON, R. J. Citizen Politics: public opinion and political parties in advanced industrial democracies. $5^{\text {a }}$ ed. Washington. CQPress, 2008.

DALTON, R. J.; WATTENBERG, M. Parties without partisans: political change in advanced industrial democracies. Ox ford: Oxford University Press, 2002.

KINZO, M. D’A. Os partidos no eleitorado: percepções políticas e laços partidários. In: KINZO, M. D.; BRAGA, M.S. (Orgs.). Eleitores e representação partidária no Brasil. São Paulo:

Humanitas, 2007.

SAMUELS, D. "As bases do Petismo". Opinião Pública", Campinas, vol.10, n² 2, p.221-241, out. 2004. 
302-318. nov. 2008

SINGER, A. "A Segunda Alma do Partido dos Trabalhadores". Novos Estudos. CEBRAP, $n^{\circ} 88$, p.89.111, nov. 2010.

VEIGA, L. F. "Os partidos brasileiros na perspectiva dos eleitores: mudanças e continuidades na identificação partidária e na avaliação das principais legendas após 2002". Opinião Pública, Campinas, vol.13, n² 2, p. 340-365, nov.2007.

VENTURI, G. "PT 30 anos: Crescimento e mudanças na preferência partidária". Revista Perseu, $n^{\circ}$ 5, p.196-214, jun. 2010.

Luciana Veiga - lucveiga@terra.com.br

Recebido para publicação em setembro de 2011.

Aprovado para publicação em outubro de 2011. 